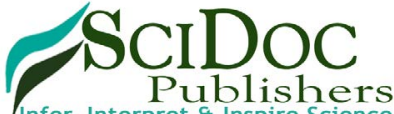

Publishers

International Journal of Anesthesiology \& Research (IJAR)

ISSN 2332-2780

\title{
Effect of Low Dose Midazolam with Low Dose Dexmedetomidine on Bradycardia and Sedation after Spinal Block: A Prospective Case Control Study
}

\author{
Research Article
}

Manju Jha ${ }^{1}$, Prashant Rai ${ }^{*}$, Bhumika ${ }^{2}$

${ }^{1}$ Professor and HOD, Department of Anaesthesiology and Critical Care, Pravara Institute of Medical Sciences, Loni, Maharashtra, India. ${ }^{2}$ MD Scholar, Department of Anaesthesiology and Critical Care, Pravara Institute of Medical Sciences, Loni, Maharashtra, India.

Abstract

Introduction: Sedation makes it convenient for the patient, the anaesthesiologist and the surgeon during surgeries under regional anaesthesia. Midazolam in doses of $0.05 \mathrm{mg} / \mathrm{Kg}$ produces good sedation and excellent amnesia but has no specific analgesic properties and causes depression of upper airway muscle tone in the elderly, resulting in a higher incidence of airway obstruction. Midazolam is commonly used drug for sedation during regional anaesthesia, which produces good sedation and excellent amnesia but causes upper airway obstruction and respiratory depression. Dexmedetomidine has been used as a sedative for various surgical and medical procedures, but loading dose of $1 \mu \mathrm{g} / \mathrm{kg}$ has been associated with higher incidences of bradycardia, whereas lower doses produce inadequate sedation.

Aim: To evaluate the effect of low dose midazolam on bradycardia and sedation during low dose dexmedetomidine infusion after spinal block.

Methodology: In this prospective case control study, 80 patients undergoing surgeries under spinal anaesthesia were studied under two groups, Group D ( $\mathrm{n}=40)$ who received $1 \mathrm{mcg} / \mathrm{kg}$ dexmedetomidine as loading dose and Group DM ( $\mathrm{n}=40$ ) who received inj.midazolam $0.025 \mathrm{mg} / \mathrm{kg}$ along with $0.5 \mathrm{mcg} / \mathrm{kg}$ dexmedetomidine as loading dose. Both the groups were maintained by continuous infusion of dexmedetomidine at $0.04 \mathrm{mcg} / \mathrm{kg} / / \mathrm{hr}$. All patients were monitored for heart rate, mean arterial pressure, respiratory rate, oxygen saturation, Observer's Assessment of Alertness/Sedation Scale (OAA/S) and complications.

Results: Mean heart rate was significantly lower in group D compared to group DM after 5 and 10 min of loading $(\mathrm{P}<0.0001)$. Incidence of bradycardia requiring Atropine was significantly higher $(\mathrm{P}=0.0011)$ in group $\mathrm{D}(22 / 40)$ than group DM $(7 / 40)$. $\mathrm{OAA} / \mathrm{S}$ score was significantly lower in group $\mathrm{DM}$ at 5 minutes $(\mathrm{P}=0.0049)$ and 10 minutes $(\mathrm{P}=0.0004)$. Other hemodynamic variables were comparable in both groups.

Conclusion: Low dose Midazolam with low dose Dexmedetomidine offered better results for bradycardia and sedation compared to routine dose of Dexmedetomidine alone.

Keywords: Dexmedetomidine; Midazolam; Bradycardia; Sedation; Spinal Block.

\section{Introduction}

Regional anaesthesia has many advantages like maintaining spontaneous breathing, relaxing necessary muscles for surgery, providing post-operative analgesia, avoiding the risks of intubation and pulmonary aspiration [1]. Staying awake, early family contact, and early food intake are major advantages from patients point of view [2]. However, the fear of surgery complemented with strange surroundings of the operation theatre, sophisticated machines and masked faces of strange personals makes the patient uncomfortable and fearful $[3,4]$. Continuous supine position for a prolonged duration and inability to move the body during regional anaesthesia further increases the discomfort causing many patients to panic [5]. Sedation has been shown to increase patient satisfaction and acceptance of regional anaesthesia [6, 7]. Sedation makes it convenient for the patient, the anaesthesiologist and the surgeon during surgeries under regional anaesthesia.

The goals of sedation during regional anesthesia include rapid achievement of adequate sedation, its maintenance at a constant level during the surgical procedure and awakening the patient quickly at the end. Many techniques and drug regimens have been

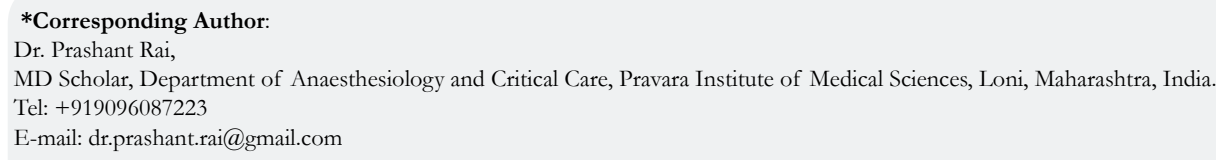

Citation: Manju Jha, Prashant Rai, Bhumika R. Effect of Low Dose Midazolam with Low Dose Dexmedetomidine on Bradycardia and Sedation after Spinal Block: A Prospective Case Control Study. Int J Anesth Res. 2018;6(2):500-508. doi: http://dx.doi.org/10.19070/2332-2780-18000101

Copyright: Prashant Rai ${ }^{\circ}$ 2018. This is an open-access article distributed under the terms of the Creative Commons Attribution License, which permits unrestricted use, distribution and reproduction in any medium, provided the original author and source are credited. 
tried for providing adequate sedation during regional anaesthesia [8-10]. Continuous infusions have been proven to produce lesser side effects, faster recovery, easy controllability over the desired depth of sedation and, should the regional block prove to be ineffective, easy conversion to general anesthesia $[11,12]$.

Midazolam has a fast onset and short recovery time, because of which it is one of the most widely used sedatives in spinal anesthesia. Midazolam in doses of $0.05 \mathrm{mg} / \mathrm{Kg}$ produces good sedation and excellent amnesia but has no specific analgesic properties and causes depression of upper airway muscle tone in the elderly, resulting in a higher incidence of airway obstruction [13-15].

Dexmedetomidine, Alpha 2 -adrenergic agonist has both analgesic and sedative properties, when used as an adjuvant to regional anesthesia $[16,17]$. They potentiate the effect of local anesthetics and prolong the duration of both motor, sensory spinal blockade and postoperative analgesia [18-20]. Other claimed advantages include minimal respiratory depression with cardio-protection, neuroprotection and renoprotection [21]. Hence dexmedetomidine has been used as a sedative for various purposes, including ICU sedation, awake fiber-optic intubation, various surgical and medical procedures. In general practice dexmedetomidine needs to be given as an initial loading dose of up to $1 \mu \mathrm{g} / \mathrm{kg}$ followed by a continuous infusion. But during the initial loading period or too rapid administration can lead to bradycardia due to sympatholytic effects [22-27], and using dose lesser than this cause inadequate sedation. Study by Yun-Sic Bang et al., [28], suggests adding low dose Midazolam and reducing Dexmedetomidine loading dose reduce chances of bradycardia while maintaining adequate sedation. However, no other study has been conducted on this subject. The present study is to evaluate the effect of low dose midazolam with low dose dexmedetomidine on bradycardia and sedation during dexmedetomidine infusion after spinal block.

\section{Aims and Objectives}

Aim of this study is to evaluate effects of low dose midazolam on bradycardia and sedation during dexmedetomidine infusion.

\section{Methodology}

This double blinded, prospective case control study was conducted after obtaining the institutional ethical committee clearance \& written informed consent from the patient. 80 patients of either gender between 18 to 60 years of age, belonging to ASA grade I \& II, undergoing surgeries under spinal anaesthesia at P.R.H. Loni, willing for study and sedation after spinal block were included for the study. Patients with known hypersensitivity to study drugs, on $\beta$-blockers or anti-coagulants, with psychiatric disorder, third degree heart block, hypotension (mean arterial pressure < $70 \mathrm{mmHg}$ ), bradycardia (baseline heart rate $<60$ beats $/ \mathrm{min}$ ), pregnant or breast feeding female were not included in the study. All patients were pre-medicated tab. Ranitidine $150 \mathrm{mg}$ orally on the night before surgery and kept nil orally from midnight. On the day of surgery intravenous access secured with 18-gauge venous cannula and preloading with $10 \mathrm{ml} / \mathrm{kg}$ of lactated Ringer's solution was done.

After noting the base line readings, patients were administered spinal block under aseptic precautions using 27G Quincke's needle, in left lateral position at $\mathrm{L}_{3}-\mathrm{L}_{4}$ level with hyperbaric Inj. Bupivacaine $13 \mathrm{mg}+25$ micrograms Inj. Fentanyl. Patient developing bradycardia (HR $<50 \mathrm{bpm}$ ) or hypotension (MAP $<60 \mathrm{~mm} \mathrm{Hg}$ or fall in MAP more than 20\%) after spinal block were managed and omitted from the study. After the confirmation of successful spinal anesthesia with adequate level of blockade, sedation was administered. Patients were studied under two groups depending on the type of sedation received. Group DM ( $n=40)$ - received Inj. Midazolam $0.025 \mathrm{mg} / \mathrm{kg}$ (diluted up to $4 \mathrm{cc}$ in normal saline) intravenously and Inj. Dexmedetomidine $0.5 \mu \mathrm{g} / \mathrm{kg}$ intravenously over a period of $10 \mathrm{~min}$ as loading dose followed by continuous infusion of $0.4 \mu \mathrm{g} / \mathrm{kg} / \mathrm{hr}$.Group D $(\mathrm{n}=40)$ - received $4 \mathrm{cc}$ of normal saline intravenously and Inj. Dexmedetomidine $1 \mu \mathrm{g} / \mathrm{kg}$ intravenously over a period of $10 \mathrm{~min}$ as loading dose followed by continuous infusion of $0.4 \mu \mathrm{g} / \mathrm{kg} / \mathrm{hr}$. Study drugs were prepared by anesthesiologist not involved in data recording, thus patient and investigator were blinded from the study drugs. All patients received oxygen at $5 \mathrm{~L} / \mathrm{min}$ via face mask and intravenous Ringers lactate solution for maintenance. Observer's Assessment of Alertness/Sedation Scale (OAA/S) was used for assessment of sedation level.

Heart rate (HR), Mean arterial pressure (MAP), respiratory rate (RR), oxygen saturation (SpO2) and the Observer's Assessment of Alertness/Sedation Scale (OAA/S) were recorded at baseline (T1), after spinal block (T2), before dexmedetomidine administration (T3), after dexmedetomidine administration every 5 mins till first $20 \mathrm{~min}$ (T5, T10, T15, T20) and every $20 \mathrm{~min}$ till $80 \mathrm{~min}$ (T40, T60, T80). Inadequate sedation (OAA/S > 3) after 15 minutes of starting infusion were managed by rescue midazolam $(0.5 \mathrm{mg}$ intravenously) and repeated whenever required to maintain $\mathrm{OAA} / \mathrm{S}$ $<3$. Side effects at any point during the surgery were documented and managed. In case of bradycardia ( $\mathrm{HR}<50 \mathrm{bpm})$ Inj. Atropine Sulphate $0.5 \mathrm{mg}$ was given intravenously, for hypotension (MAP $<60 \mathrm{~mm} \mathrm{Hg}$ or fall in MAP more than 20\%) Inj. Ephedrine $\mathrm{HCl}$ $5 \mathrm{mg}$ in incremental doses were given, for respiratory depression (rate $<8$ or $\mathrm{SpO} 2<90 \%$ ) the depth and rate of respiration was increased with painful stimuli, airway insertion and stopping the infusion. Nausea/Vomiting by Inj. Ondansetron $4 \mathrm{mg}$ intravenously. The infusion was discontinued after completion of surgery and

Table 1. Observer's assessment of alertness/sedation (OAA/S) scale.

\begin{tabular}{|c|c|}
\hline Observation & Score level \\
\hline Responds readily to name spoken in normal tone & 5 \\
\hline Lethargic response to name spoken in normal tone & 4 \\
\hline Responds only after name is called loudly and/or repeatedly & 3 \\
\hline Responds only after mild prodding or shaking & 2 \\
\hline Does not respond to mild prodding or shaking & 1 \\
\hline
\end{tabular}


patients were shifted to post-anaesthesia care unit (PACU) till $\mathrm{OAA} / \mathrm{S}=5$ was achieved. MAP, HR, SpO2, OAA/S were noted on arrival and at discharge from PACU. Time taken for OAA/S score to reach 5 after stopping the study drug was noted. Patients were observed for any complications postoperatively for $24 \mathrm{hrs}$.

\section{Statistical Analysis}

All data were entered into a proforma in excel sheet (MS Office 2016) and statistical analysis was done using SPSS software (Statistical Package for Social Science [SPSS] version 19.0 for Windows, SPSS, Inc). Chi square test, students unpaired t-test was used for inter group comparisons and repeated measures ANOVA for within the group comparisons. $\mathrm{P}$ value $<0.05$ was considered statistically significant.

\section{Observations and Results}

Effect of spinal anaesthesia was adequate in all the patients and none required administration of general anaesthesia, none of the patients were excluded from the study after spinal block and thus all 80 patients were considered for evaluation process (40 in each group).

Significant fall in mean heart rate was observed in both groups $(\mathrm{P}<0.05)$ after 5 min of dexmedetomidine loading dose. Mean heart rate was significantly lower in group D compared to group $\mathrm{DM}$ at 5 and $10 \mathrm{~min}$ of loading $(\mathrm{P}<0.0001) .22$ patients $(55 \%)$ in group $\mathrm{D}$ required Atropine intraoperatively as compared to 7 patients $(17.50 \%)$ in group DM and the difference was statistically significant $(\mathrm{P}=0.0011)$.
Significant fall in mean MAP was observed in both groups $(\mathrm{P}<$ $0.05)$ after spinal block and 5 min of dexmedetomidine loading dose. Fall in both groups were comparable at all-time intervals.

Mean Respiratory Rate and mean SpO2 were comparable in both the groups at all-time intervals and no respiratory depression was observed in either group.

Significant fall in mean OAA score was observed in both groups $(\mathrm{P}<0.05)$ after 5 min of dexmedetomidine loading dose. Mean $\mathrm{OAA} / \mathrm{S}$ score was significantly lower in group DM at 5 minutes $(\mathrm{P}=0.0049)$ and 10 minutes $(\mathrm{P}=0.0004)$. However, it remained comparable in both groups during rest of the intraoperative period. 2 patients in group DM and 3 in group D required midazolam supplementation to maintain adequate sedation, however the difference was insignificant $(\mathrm{P}=0.6442)$.

All hemodynamic variables were comparable in both groups during post-operative period. Mean recovery time after stopping dexmedetomidine infusion was $39.05 \pm 19.07$ minutes in group D and $34.13 \pm 17.21$ minutes in group DM with no significant difference $(P=0.229)$. No other complication was reported in any patient during intraoperative and post-operative period.

\section{Discussion}

In our study both the groups were comparable for age, sex, height, weight, duration of surgery.

Dexmedetomidine provides excellent sedation without respira-

Table 2. Demographic Profile.

\begin{tabular}{|c|c|c|c|c|}
\hline & Group D & Group DM & Statistical test & P Value \\
\hline Age $($ year $)$ & $35.88 \pm 11.5$ & $38.4+8.97$ & Unpaired t-test & 0.277 \\
\hline Gender $(\mathrm{M} / \mathrm{F})$ & $23 / 17$ & $19 / 21$ & Chi square test & 0.502 \\
\hline Weight $(\mathrm{Kg})$ & $66.78+10.34$ & $63.35+10.98$ & Unpaired t-test & 0.1549 \\
\hline Height $(\mathrm{cm})$ & $163.13+9.51$ & $160.45+9.18$ & Unpaired t-test & 0.2046 \\
\hline ASA grading $(\mathrm{I} / \mathrm{II})$ & $21 / 19$ & $18 / 22$ & Chi square test & 0.655 \\
\hline
\end{tabular}

Both groups were comparable in terms of age, gender, weight, height and ASA grading $(\mathrm{p}>0.05)$.

Table 3. Mean HR (Intraoperative).

\begin{tabular}{|c|c|c|c|c|c|}
\hline \multirow{2}{*}{ Time Interval } & \multicolumn{2}{|c|}{ GROUP D } & \multicolumn{2}{c|}{ GROUP DM } & \multirow{2}{*}{ P VALUE } \\
\cline { 2 - 5 } & MEAN & S.D. & MEAN & S.D. & \\
\hline T1 & 78.23 & 7.96 & 80.05 & 7.14 & 0.2838 \\
\hline T2 & 81.50 & 8.31 & 83.10 & 7.20 & 0.3601 \\
\hline T3 & 79.60 & 8.71 & 81.03 & 7.03 & 0.4232 \\
\hline T5 & 59.25 & 8.09 & 67.10 & 6.98 & $<0.0001$ \\
\hline T10 & 63.93 & 10.42 & 65.30 & 5.66 & $<0.0001$ \\
\hline T15 & 66.35 & 7.86 & 64.35 & 5.52 & 0.1919 \\
\hline T20 & 64.78 & 6.73 & 64.83 & 4.33 & 0.9686 \\
\hline T40 & 65.25 & 5.79 & 66.35 & 4.55 & 0.3479 \\
\hline T60 & 66.28 & 5.8 & 67.40 & 4.72 & 0.3444 \\
\hline T80 & 67.33 & 5.97 & 68.25 & 4.49 & 0.4395 \\
\hline
\end{tabular}


Graph 1. Intraoperative mean HR.

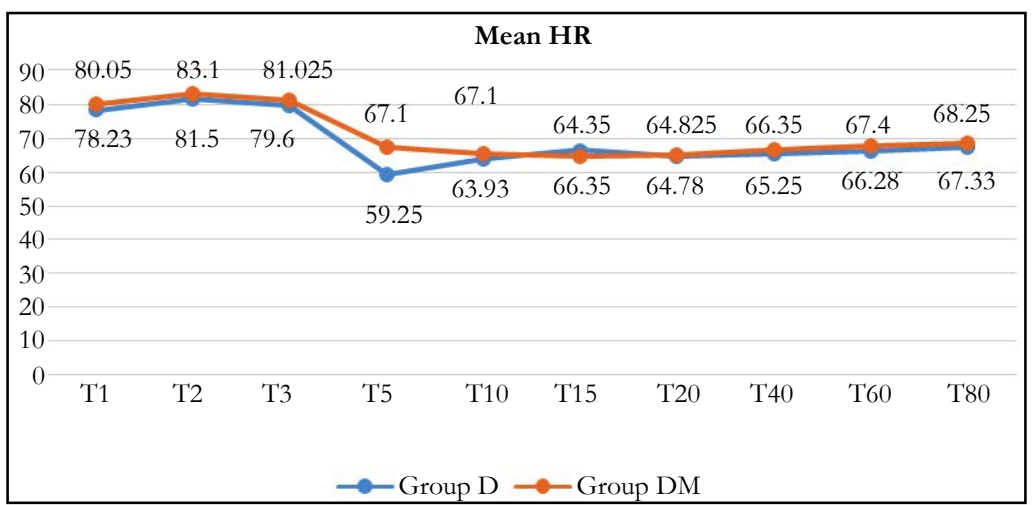

Graph 2. Patients requiring Atropine.

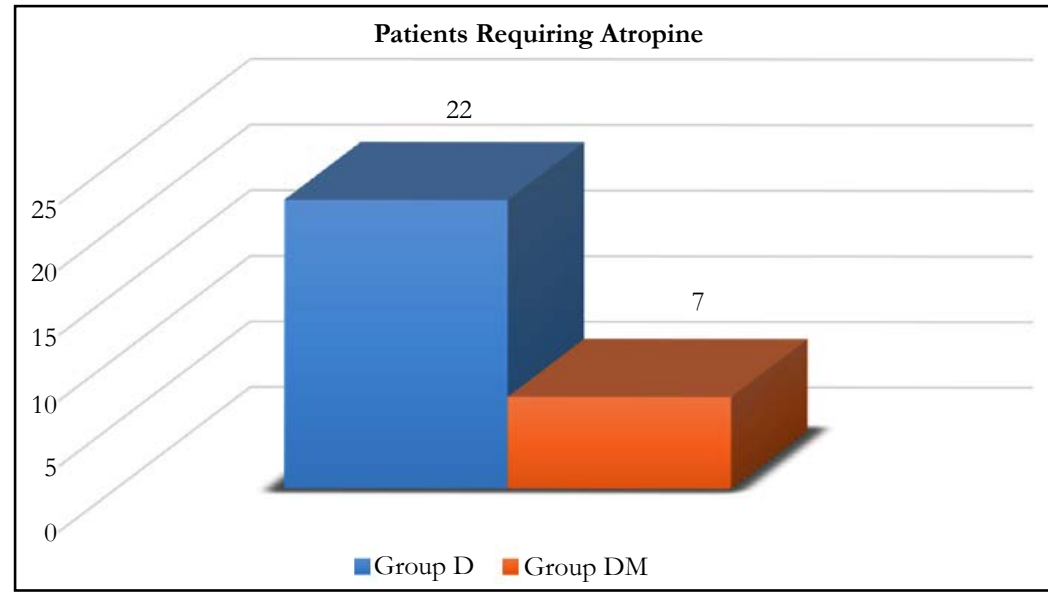

Table 4. Intraoperative mean MAP.

\begin{tabular}{|c|c|c|c|c|c|}
\hline \multirow{2}{*}{ Time Interval } & \multicolumn{2}{|c|}{ GROUP D } & \multicolumn{2}{c|}{ GROUP DM } & \multirow{2}{*}{ P VALUE } \\
\cline { 2 - 5 } & MEAN & S.D. & MEAN & S.D. & \\
\hline T1 & 91.28 & 11.60 & 92.40 & 10.00 & 0.6435 \\
\hline T2 & 85.40 & 11.82 & 85.05 & 9.47 & 0.8842 \\
\hline T3 & 82.30 & 11.77 & 83.15 & 9.53 & 0.7236 \\
\hline T5 & 80.45 & 12.21 & 80.90 & 9.64 & 0.8553 \\
\hline T10 & 79.30 & 11.81 & 79.68 & 9.75 & 0.9105 \\
\hline T15 & 78.65 & 11.15 & 79.65 & 8.99 & 0.6599 \\
\hline T20 & 78.00 & 10.87 & 79.03 & 8.75 & 0.6436 \\
\hline T40 & 78.95 & 10.92 & 80.48 & 9.08 & 0.4991 \\
\hline T60 & 79.68 & 10.87 & 81.40 & 9.09 & 0.4438 \\
\hline T80 & 81.05 & 11.34 & 82.68 & 9.17 & 0.4830 \\
\hline
\end{tabular}

tory depression and also has added advantage of prolonged duration of motor \& sensory blockade and postoperative analgesia after spinal block [18-20].

Multiple studies have reported higher incidence of bradycardia (more than 40\%) during initial loading with dexmedetomidine due to sympathetic blockade [22-27]. It has been suggested that dexmedetomidine has a dose-dependent effect on hemodynamic profile which may be altered by the loading dose [29, 30]. In our study we used dose of dexmedetomidine to reduce the incidence of bradycardia.

We observed, mean heart rate was significantly lower in group D compared to group DM at 5 and 10 min of loading $(\mathrm{P}<0.0001)$. Significantly lower incidence $(\mathrm{P}=0.0011)$ of bradycardia was observed in group DM with 7 patients $(17.50 \%)$ compared to $22 \mathrm{pa-}$ tients $(55 \%)$ in group D required atropine intraoperatively. Similar results were observed by Yun-Sic-Bang et al., who found patients requiring atropine as $15 / 33$ in group receiving $1 \mu \mathrm{g} / \mathrm{kgvs} .5 / 32$ in group receiving $0.5 \mu \mathrm{g} / \mathrm{kg}$ dexmedetomidine, $\mathrm{P}=0.009$ [28]. Mizrak et al., also observed no significant bradycardia with loading dose of $0.5 \mu \mathrm{g} / \mathrm{kg}$ before general anaesthesia [32].

The incidence of bradycardia was significantly lower in group DM compared to the group D probably because the sympatholytic action and vagal mimetic effect of dexmedetomidine is re- 
Graph 3. Intraoperative mean MAP.

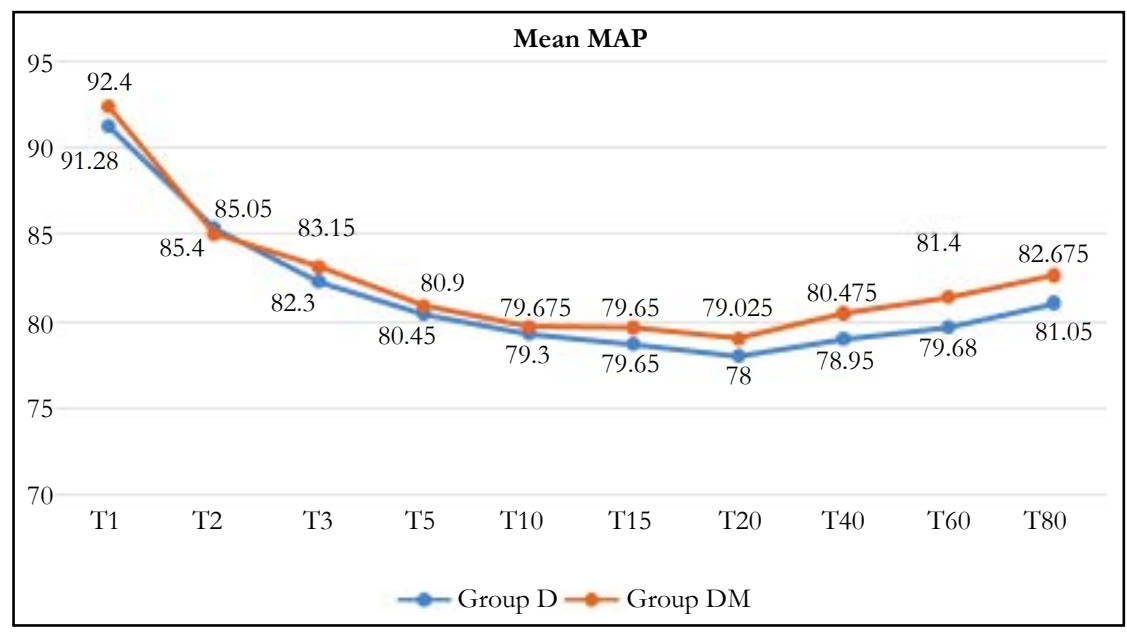

Table 5. Intraoperative mean RR.

\begin{tabular}{|c|c|c|c|c|c|}
\hline \multirow{2}{*}{ Time Interval } & \multicolumn{2}{|c|}{ GROUP D } & \multicolumn{2}{c|}{ GROUP DM } & \multirow{2}{*}{ P VALUE } \\
\cline { 2 - 5 } & MEAN & S.D. & MEAN & S.D. & \\
\hline T1 & 16.03 & 2.81 & 15.73 & 2.18 & 0.5958 \\
\hline T2 & 17.00 & 2.32 & 16.63 & 2.22 & 0.3525 \\
\hline T3 & 16.58 & 2.36 & 15.98 & 2.15 & 0.2045 \\
\hline T5 & 16.25 & 2.17 & 15.73 & 2.22 & 0.2326 \\
\hline T10 & 16.75 & 2.37 & 16.40 & 2.46 & 0.3662 \\
\hline T15 & 16.98 & 2.56 & 16.03 & 2.63 & 0.1052 \\
\hline T20 & 16.28 & 2.01 & 15.38 & 2.72 & 0.0968 \\
\hline T40 & 15.68 & 2.29 & 15.15 & 2.67 & 0.3478 \\
\hline T60 & 15.08 & 2.48 & 14.50 & 2.80 & 0.3038 \\
\hline T80 & 15.40 & 2.57 & 14.93 & 3.17 & 0.3890 \\
\hline
\end{tabular}

Graph 4. Intraoperative mean RR.

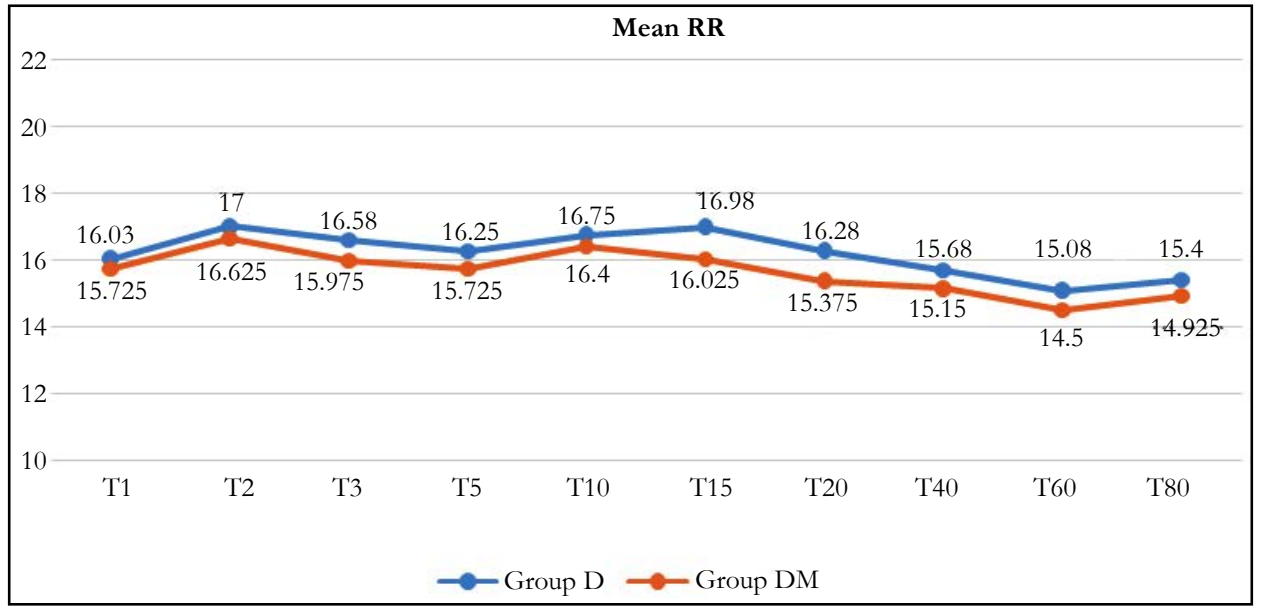

duced due to the low dose.

Loading with dexmedetomidine in dose of $1 \mu \mathrm{g} / \mathrm{kg}$ provides faster and better sedation compared to $0.5 \mu \mathrm{g} / \mathrm{kg}[29,30]$. There have been reports of the synergistic enhancement of their sedative effects when midazolam and dexmedetomidine are used in combination [32]. In our study we used low dose midazolam $0.025 \mathrm{mg} /$ $\mathrm{kg}$ as adjuvant to low dose $0.5 \mu \mathrm{g} / \mathrm{kg}$ dexmedetomidine for loading in group DM.
Using OAA/S scale to assess sedation, we observed mean $\mathrm{OAA} / \mathrm{S}$ score was significantly lower in group DM at 5 minutes $(\mathrm{P}=0.0049)$ and 10 minutes $(\mathrm{P}=0.0004)$. Thus faster and better onset in group receiving midazolam and dexmedetomidine. $\mathrm{OAA} / \mathrm{S}$ was comparable in both groups during rest of the intraoperative period and number of patients requiring rescue midazolam in both the groups were comparable. Similar results were observed by Yun-Sic-Bang et al., who found significantly lower $\mathrm{BIs}$ and $\mathrm{OAA} / \mathrm{S}$ at 5 and $10 \mathrm{~min}$ after loading in group receiving $0.5 \mu \mathrm{g} / \mathrm{kg}$ dexmedetomidine. 
Table 6. Intraoperative mean SP02.

\begin{tabular}{|c|c|c|c|c|c|}
\hline & \multicolumn{2}{|c|}{ GROUP D } & \multicolumn{2}{c|}{ GROUP DM } & \multirow{2}{*}{ P VALUE } \\
\cline { 2 - 5 } & MEAN & S.D. & MEAN & S.D. & \\
\hline T1 & 98.88 & 0.79 & 98.85 & 0.77 & 0.8864 \\
\hline T2 & 98.98 & 0.80 & 98.73 & 0.85 & 0.1787 \\
\hline T3 & 99.03 & 0.80 & 99.13 & 0.88 & 0.5309 \\
\hline T5 & 98.88 & 0.88 & 99.23 & 0.77 & 0.0621 \\
\hline T10 & 99.08 & 0.83 & 99.08 & 0.92 & 0.999 \\
\hline T15 & 99.23 & 0.77 & 99.18 & 0.87 & 0.2719 \\
\hline T20 & 99.08 & 0.83 & 98.88 & 0.79 & 0.2728 \\
\hline T40 & 98.75 & 0.71 & 99.05 & 0.85 & 0.0892 \\
\hline T60 & 99.15 & 0.74 & 99.30 & 0.76 & 0.3718 \\
\hline T80 & 99.08 & 0.80 & 99.03 & 0.86 & 0.7884 \\
\hline
\end{tabular}

Graph 5. Intraoperative mean SP02.

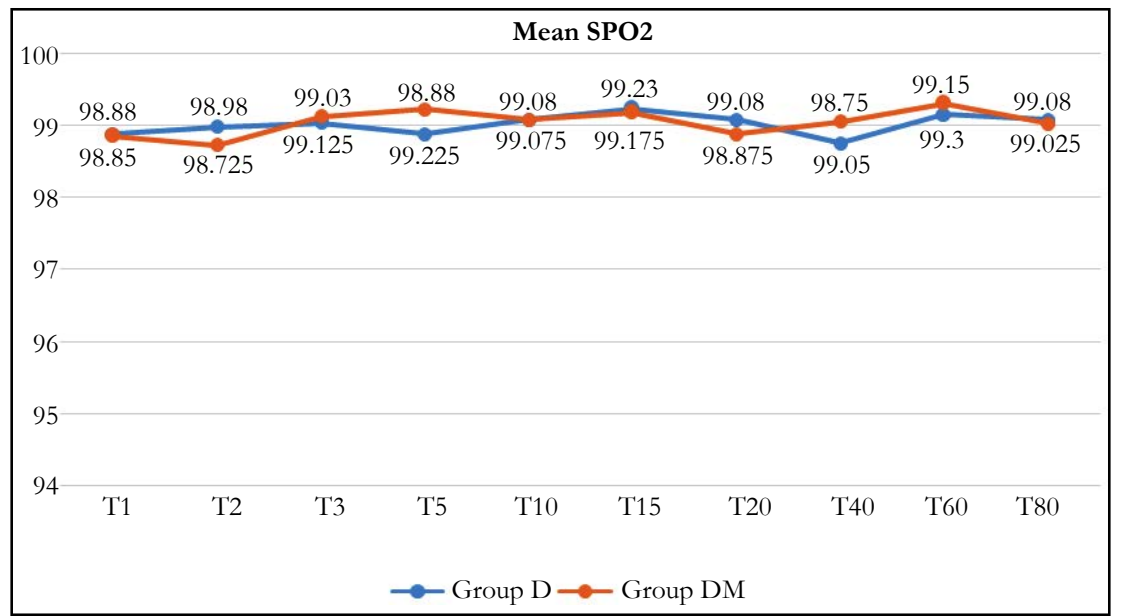

Table 7. Mean OAA/S score (Intraoperative).

\begin{tabular}{|c|c|c|c|c|c|}
\hline \multirow{2}{*}{ Time Interval } & \multicolumn{2}{|c|}{ GROUP D } & \multicolumn{2}{c|}{ GROUP DM } & \multirow{2}{*}{ P VALUE } \\
\cline { 2 - 5 } & MEAN & S.D. & MEAN & S.D. & \\
\hline T1 & 5.00 & 0.00 & 5.00 & 0.00 & -- \\
\hline T2 & 5.00 & 0.00 & 5.00 & 0.00 & -- \\
\hline T3 & 5.00 & 0.00 & 5.00 & 0.00 & -- \\
\hline T5 & 4.43 & 0.71 & 3.93 & 0.83 & 0.0049 \\
\hline T10 & 3.48 & 0.75 & 2.83 & 0.81 & 0.0004 \\
\hline T15 & 2.58 & 0.64 & 2.48 & 0.78 & 0.5328 \\
\hline T20 & 2.40 & 0.50 & 2.38 & 0.67 & 0.8497 \\
\hline T40 & 2.25 & 0.49 & 2.28 & 0.55 & 0.8318 \\
\hline T60 & 2.33 & 0.53 & 2.35 & 0.48 & 0.8253 \\
\hline T80 & 2.48 & 0.55 & 2.53 & 0.60 & 0.6993 \\
\hline
\end{tabular}

Dexmedetomidine being a a2-adrenergic agonist causes an a2adrenoceptor induced vasoconstrictive response in the peripheral vasculature which increases the blood pressure initially. Then due to both centrally and peripherally mediated sympatholytic action, hypotension follows [33]. This decrease in the sympathetic outflow and circulating catecholamine levels [25-27] as well as the vagal mimetic effect [34] of dexmedetomidine cause a decrease in the HR and BP.
In our study we observed Significant fall in mean MAP in both groups $(\mathrm{P}<0.05)$ after spinal block and 5 min of dexmedetomidine loading dose. Fall in both groups were comparable at all-time intervals.

Respiratory depression was not observed in any of the group, probably due to use of low dose of midazolam $(0.025 \mathrm{mg} / \mathrm{kg})$. 
Graph 6. Mean OAA/S.

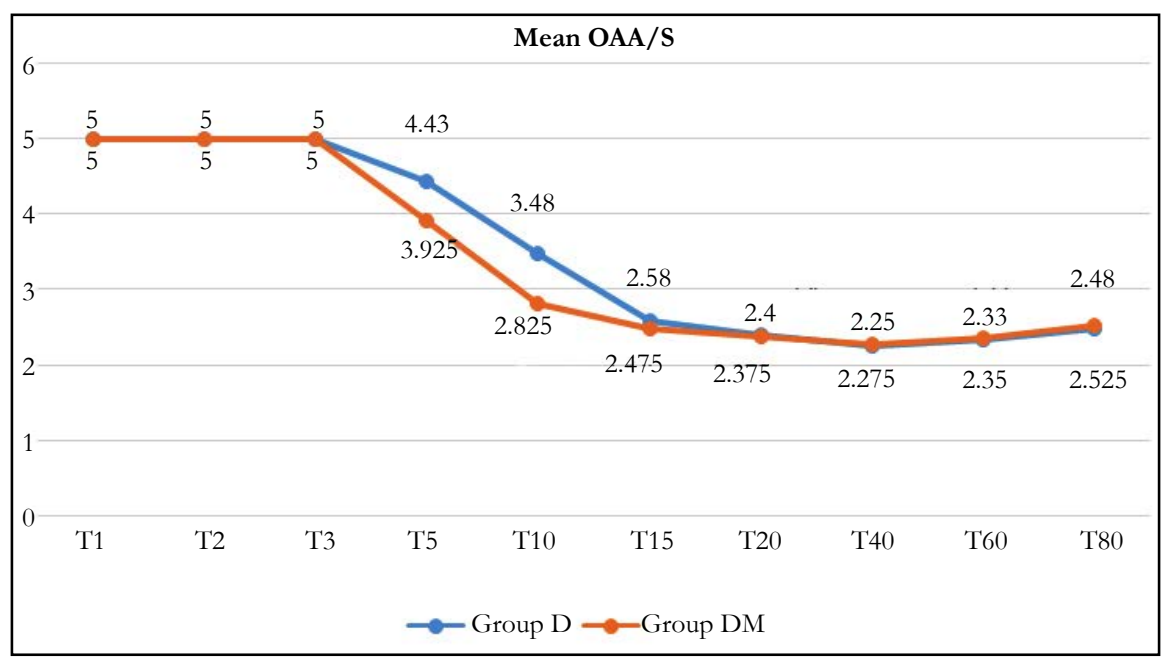

Graph 7. Patients requiring rescue midazolam.

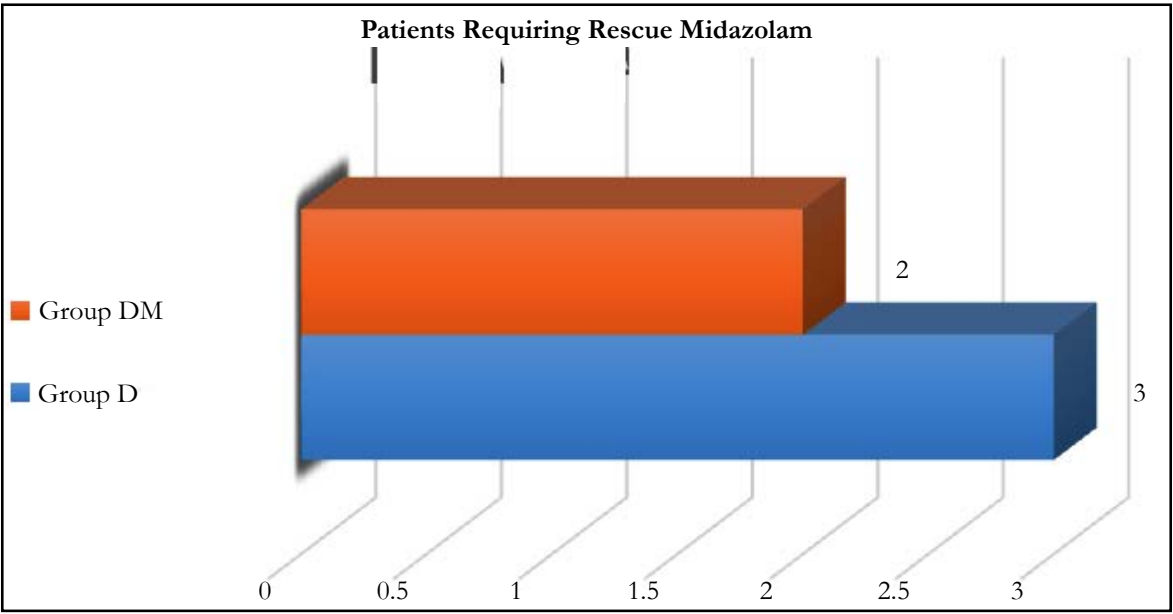

Table 8. Post-operative monitoring.

\begin{tabular}{|c|c|c|c|c|c|c|}
\hline & GROUP D & GROUP DM & \multirow{2}{*}{ P VALUE } \\
\cline { 2 - 5 } & MEAN & SD & MEAN & SD & \\
\hline \multicolumn{7}{|c|}{ HEART RATE } \\
\hline At Arrival & 70.43 & 6.19 & 71.38 & 5.18 & 0.4591 \\
\hline At Discharge & 70.88 & 6.33 & 72.43 & 5.27 & 0.2374 \\
\hline \multicolumn{7}{|c|}{ MEAN ARTERIAL PRESSURE } \\
\hline At Arrival & 83.20 & 11.29 & 83.73 & 9.22 & 0.8203 \\
\hline At Discharge & 84.08 & 11.28 & 84.18 & 9.22 & 0.9665 \\
\hline RESPIRATORY RATE \\
\hline At Arrival & 15.55 & 2.36 & 15.23 & 2.31 & 0.5362 \\
\hline At Discharge & 16.00 & 2.39 & 15.5 & 2.36 & 0.3494 \\
\hline At Arrival & 99.05 & 0.78 & 99.15 & 0.86 & 0.589 \\
\hline At Discharge & 99.13 & 0.82 & 99.18 & 0.81 & 0.7852 \\
\hline \multicolumn{7}{|c|}{ OAA/S SCORE } \\
\hline At Arrival & 3.25 & 0.74 & 3.10 & 0.78 & 0.3804 \\
\hline At Discharge & 5.00 & 0.00 & 5.00 & 0.00 & - \\
\hline RECOVERY TIME \\
\hline Time taken for OAA/S to reach 5 & 39.05 & 19.07 & 34.13 & 17.21 & 0.229 \\
\hline
\end{tabular}


Graph 8. Mean recovery time.

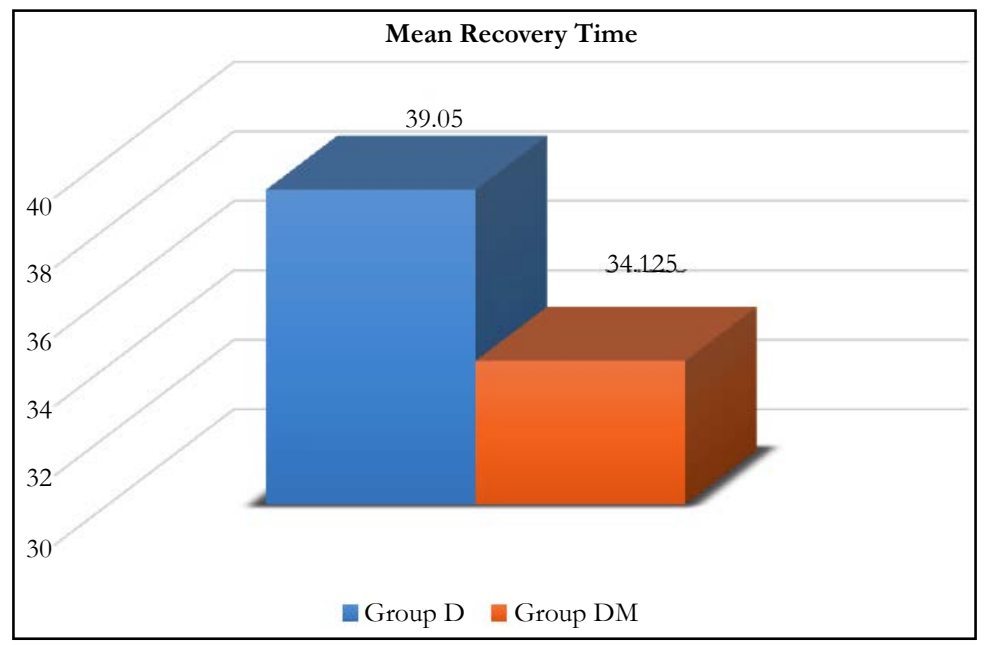

Hemodynamic variables and mean recovery time were comparable among both the groups postoperatively. No other side effects were observed in any of the group.

These findings suggest that the earlier sedation effect after the start of dexmedetomidine was achieved as a result of the administration of low dose midazolam until later sedation was achieved by dexmedetomidine. Also, both dexmedetomidine and midazolam complemented each other intraoperatively, enabling an optimal level of sedation to be achieved and maintained. More time was required to achieve optimal sedation with dexmedetomidine alone.

\section{Conclusion}

Midazolam $0.025 \mathrm{mg} / \mathrm{kg}$ with a halved loading dose $(0.5 \mu \mathrm{g} / \mathrm{kg})$ of dexmedetomidine was superior in terms of producing sedation and lower incidence of bradycardia than with dexmedetomidine alone $(1 \mu \mathrm{g} / \mathrm{kg})$, without causing respiratory depression or hemodynamic instability.

\section{References}

[1]. Hwoe G, Seung HB, Seong WB, Hae KK, Sang WS, Kyung HK. Optimal dose of dexmedetomidine for sedation during spinal anesthesia. Korean J Anesthesiol. 2013 May; 64(5):426-431.

[2]. De JA, Valia JC, Gil A, Bolinches R. Predictors of patient satisfaction with regional anesthesia. Reg Anesth. 1995 Nov-Dec;20(6):498-505. PubMed PMID: 8608068.

[3]. Asehnoune K, Albaladejo P, Smail N, Heriche C, Sitbon P, et al. Information and anesthesia: what does the patient desire?. Ann Fr Anesth Reanim. 2000 Oct;19(8):577-81. PubMed PMID: 11098318.

[4]. Badner NH, Nielson WR, Munk S, Kwiatkowska C, Gelb AW. Preoperative anxiety: detection and contributing factors. Can J Anaesth. 1990 May;37(4 Pt 1):444-7. PubMed PMID: 2340614.

[5]. Schnider TW, Minto CF. Predictors of onset and offset of drug effect. Eur J Anaesthesiol Suppl. 2001;23:26-31. PubMed PMID: 11766242.

[6]. Wu CL, Naqibuddin M, Fleisher LA. Measurement of patient satisfaction as an outcome of regional anesthesia and analgesia: a systematic review. Reg Anesth Pain Med. 2001 May-Jun;26(3):196-208. PubMed PMID: 11359218.

[7]. Practice guidelines for sedation and analgesia by non-anesthesiologists. American Society of Anesthesiologists Task Force on Sedation and Analgesia by Non-Anesthesiologists. Anesthesiology. 2002 Apr;96(4):1004-17. PubMed PMID: 11964611.

[8]. Höhener D, Blumenthal S, Borgeat A. Sedation and regional anaesthesia in the adult patient. Br J Anaesth. 2008 Jan;100(1):8-16. PubMed PMID: 18070783

[9]. Helgeson LE. Sedation during regional anesthesia: inhalation versus intra- venous. Curr Opin Anaesthesiol. 2005 Oct;18(5):534-9. PubMed PMID: 16534289.

[10]. Némethy M, Paroli L, Williams-Russo PG, Blanck TJ. Assessing sedation with regional anesthesia: inter-rater agreement on a modified Wilson sedation scale. Anesth Analg. 2002 Mar;94(3):723-8; table of contents. PubMed PMID: 11867405

[11]. Smith I, Monk TG, White PF, Ding Y. Propofol infusion during regional anesthesia: sedative, amnestic, and anxiolytic properties. Anesth Analg. 1994 Aug;79(2):313-9. PubMed PMID: 7639371.

[12]. Casati A, Fanelli G, Casaletti E, Colnaghi E, Cedrati V, Torri G. Clinical assessment of target-controlled infusion of propofol during monitored anesthesia care. Can J Anaesth. 1999 Mar;46(3):235-9. PubMed PMID: 10210047.

[13]. De Andres J, Bolinches R. Comparative study of propofol and midazolam for sedation in regional anesthesia. Rev Esp Anestesiol Reanim. 1993 NovDec;40(6):354-9. PubMed PMID: 8134676.

[14]. Leiter JC, Knuth SL, Krol RC, Bartlett Jr D. The effect of diazepam on genioglossal muscle activity in normal human subjects. Am Rev Respir Dis. 1985 Aug;132(2):216-9. PubMed PMID: 3927805.

[15]. Montravers P, Dureuil B, Desmonts JM. Effects of i.v. midazolam on upper airway resistance. Br J Anaesth. 1992 Jan;68(1):27-31. PubMed PMID: 1739562.

[16]. Gabriel JS, Gordin V. Alpha 2 agonists in regional anesthesia and analgesia. Curr Opin Anaesthesiol. 2001 Dec;14(6):751-3. PubMed PMID: 17019175.

[17]. Mauro VA, Brandāo ST. Clonidine and dexmedetomidine through epidural route for post-operative analgesia and sedation in a colecistectomy. Rev Bras Anestesiol. 2004;4:1-0.

[18]. Strebel S, Gurzeler JA, Schneider MC, Aeschbach A, Kindler CH. Smalldose intrathecal clonidine and isobaric bupivacaine for orthopedic surgery: a dose-response study. Anesth Analg. 2004 Oct;99(4):1231-8, table of contents. PubMed PMID: 15385382.

[19]. Dobrydnjov I, Axelsson K, Thörn SE, Matthiesen P, Klockhoff H. Clonidine combined with small-dose bupivacaine during spinal anesthesia for inguinal herniorrhaphy: a randomized double-blinded study. Anesth Analg. 2003 May;96(5):1496-503, table of contents. PubMed PMID: 12707157.

[20]. Sethi BS, Samuel M, Sreevastava D. Efficacy of analgesic effects of low dose intrathecal clonidine as adjuvant to bupivacaine. Indian journal of Anaesthesia. 2007 Sep 1:51(5):415.

[21]. Panzer O, Moitra V, SladenRN. Pharmacology of sedative-analgesic agents: Dexmedetomidine, remifentanil, ketamine, volatile anesthetics, and the role of peripheral mu antagonists. Crit Care Clin. 2009 Jul;25(3):451-69, vii. doi: 10.1016/j.ccc.2009.04.004. PubMed PMID: 19576524.

[22]. Grant SA, Breslin DS, MacLeod DB, Gleason D, Martin G. Dexmedetomidine infusion for sedation during fiberoptic intubation: a report of three cases. J Clin Anesth. 2004 Mar;16(2):124-6. PubMed PMID: 15110375.

[23]. Riker RR, Shehabi Y, Bokesch PM, Ceraso D, Wisemandle W; SEDCOM (Safety and Efficacy of Dexmedetomidine Compared With Midazolam) Study Group. Dexmedetomidine vs midazolam for sedation of critically ill patients: a randomized trial. JAMA. 2009 Feb 4;301(5):489-99. doi: 10.1001/jama.2009.56. Epub 2009 Feb 2. PubMed PMID: 19188334.

[24]. Hong JY, Kim WO, Yoon Y, Choi Y, Kim SH, Kil HK. Effects of intravenous dexmedetomidine on low-dose bupivacaine spinal anaesthesia in elderly patients. Acta Anaesthesiol Scand. 2012 Mar;56(3):382-7. doi 
10.1111/j.1399-6576.2011.02614.x. Epub 2012 Jan 4. PubMed PMID: 22220945.

[25]. Ebert TJ, Hall JE, Barney JA, Uhrich TD, Colinco MD. The effects of increasing plasma concentrations of dexmedetomidine in humans. Anesthesiology. 2000 Aug;93(2):382-94. PubMed PMID: 10910487.

[26]. Talke P, Chen R, Thomas B, Aggarwall A, Gottlieb A, Kallio A. The hemodynamic and adrenergic effects of perioperative dexmedetomidine infusion after vascular surgery. Anesth Analg. 2000 Apr;90(4):834-9. PubMed PMID: 10735784.

[27]. Talke P, Richardson CA, Scheinin M, Fisher DM. Post-operative pharmacokinetics and sympatholytic effects of dexmedetomidine. Anesth Analg. 1997 Nov;85(5):1136-42. PubMed PMID: 9356115.

[28]. Bang YS, So E, Kim S, Chun DH. Effects of low dose midazolam on bradycardia and sedation during dexmedetomidine infusion. Int J Clin Exp Med. 2016 Jan 1;9(6):11838-44.

[29]. Lee S, Kim BH, Lim K, Stalker D, Wisemandle W, et al. Pharmacokinetics and pharmacodynamics of intravenous dexmedetomidine in healthy Korean subjects. J Clin Pharm Ther. 2012 Dec;37(6):698-703. doi: 10.1111/j.13652710.2012.01357.x. Epub 2012 May 31. PubMed PMID: 22650799.
[30]. Hong GH. Anesthesiology and Pain Medicine. the Korean Society of Anesthesiologists. In: Monitoring and anesthesia record. 2nd ed. Seoul: Ryo Moon Gak; 2010. p. 142-143

[31]. Mizrak A, Ganidagli S, Cengiz MT, Oner U, Saricicek V. The effects of DEX premedication on volatile induction of mask anesthesia (VIMA) and sevoflurane requirements. J Clin Monit Comput. 2013 Jun;27(3):329-34. doi: 10.1007/s10877-013-9440-y. Epub 2013 Feb 12. PubMed PMID: 23400425.

[32]. Bol CJ, Vogelaar JP, Tang JP, Mandema JW. Quantification of pharmacodynamic interactions between dexmedetomidine and midazolam in the rat. J Pharmacol Exp Ther. 2000 Jul;294(1):347-55. PubMed PMID: 10871332.

[33]. Bloor BC, Ward DS, Belleville JP, Maze M. Effects of intravenous dexmedetomidine in humans. II. Hemodynamic changes. Anesthesiology. 1992 Dec;77(6):1134-42. PubMed PMID: 1361311.

[34]. De Jonge A, Timmermans PB, Van Zwieten PA. Participation of cardiac presynaptic $\alpha 1$-Adrenoceptors in the bradycardiac effects of clonidine and analogues. Naunyn Schmiedebergs Arch Pharmacol. 1981 Aug;317(1):8-12. PubMed PMID: 6116198. 